\title{
Creating a Learning Information Retrieval System for Selection of Electromechanical Devices for Cleaning of Gas Emissions, Wastewater and Solid Waste
}

\author{
Iryna Shvedchykova \\ Kyiv National University of Technologies and Design \\ Kyiv, Ukraine \\ ishved@i.ua \\ Valerii Tytiuk \\ State institution of higher education \\ «Kryvyi Rih National University» \\ Kryvyi Rih, Ukraine \\ dinalt2006@gmail.com
}

\author{
Iryna Soloshych \\ Kremenchuk Mykhailo Ostrohradskyi National University \\ Kremenchuk, Ukraine \\ soloishych@gmail.com
}

\begin{abstract}
The paper suggests a new approach to building of information retrieval system to select electromechanical devices for purification of gas emission, wastewater and solid waste, based on a methodological tools of genetic systematics. The structure of genetic systematic of electromechanical equipment designed to clean exhaust gases, wastewater and solid waste is presented in the paper. The results of the research can be used in the learning process for students of natural and electrical engineering specialties.
\end{abstract}

Keywords-information retrieval system; systematics; magnetic separator; database.

\section{INTRODUCTION}

Environmental degradation requires specialists in enterprises the ability to choose appropriate electromechanical equipment for purification of gas emission, wastewater and solid waste by means of information retrieval systems. The creation of new and improvement of existing information retrieval systems is an urgent task, which difficulty increases addressing the increasing design and functional diversity of electromechanical devices.

Information retrieval system is intended to storage, processing, retrieval, distribution, transmission and giving information [1]. They are a form of automated information systems. In recent years, the information retrieval systems have not only been developing due to the technological innovations, but mostly through new approaches to the methodology of their construction. This ensures the creation of truly intelligent systems that do not only accumulate, preserve and provide online access to information, but also generate new scientific knowledge.

In modern society, there is a growing need in training future engineers and electricians who not only have professional knowledge and skills, but also can improve on their own to implement appropriate high-tech environmental technology into manufacturing. Employers prefer specialists who are able to build efficiently their professional activities using the latest technology and devices. An important factor in the formation of professional competence and personality of future specialists is the use of information retrieval systems in education when teaching specialized course. Using systematic information in the learning process will contribute to the development of scientific systematic thinking, associative memory and professional intuition in students.

\section{PROBLEM STATEMENT}

The use of information retrieval systems in learning is one of the central tasks of the system of electrical engineers' education. According to the curriculum, these students learn such disciplines of information and design orientation as: "Computers and programming", "Electrical machines", "Fundamentals of computer-aided design of electrical devices", "Electrical apparatus", "Special electrical machines and apparatus", "Test, operation and repair of electrical devices", "Computer technologies in electrical equipment design". Curriculum of these subjects provides that the students study computer-aided design and programming languages, databases and knowledge bases; explore approaches to the treatment of poorly structured information and master the skills in designing electrical devices and electromechanical systems based on their status and development.

Solving engineering problems on selection of electromechanical equipment for different conditions requires processing of large referral databases, catalogs and patent information. This is especially true of electromechanical devices for purification of gas emission, wastewater and solid 
waste, which cover a wide variety of design and functionality. Information search under these conditions is rather timeconsuming. Existing database information retrieval systems do not provide efficient searching because the approaches to their organizations are not strict. There are always either unrecorded data or data housed in multiple databases (excessive data) [2]. Therefore, in order to solve the problem of building information retrieval systems for selection of electromechanical devices for purification of gas emission, wastewater and solid waste, the new methodological approaches must be applied that would ensure completeness of the information presentation and limit its redundancy.

\section{PROPOSED APPROACH TO CREATION OF INFORMATION RETRIEVAL SYSTEM}

\section{A. Research methodology substantiation}

To solve the above-mentioned problem, it is proposed to use the methodological tools of structural and systematic approach in electromechanics, specifically, the methods of genetic systematics [2]. The use of such methods of genetic systematics as defining the boundaries of existence, composition and quantity of genetic information species and rank structure of the basic units of classes of electromechanical objects allows organizing a structured presentation of information in the form of electronic catalogs and databases. Ranked genetic systematics structure thus guarantees the completeness of information presentation and solves the problem of excessive data.

The purpose of this paper is to show the practical implementation of the methodology of genetic systematics for creating information retrieval system enabling selection of appropriate technical solutions for electromechanical equipment for purification of gas emission, wastewater and solid waste on the example of the functional class of magnetic separators.

\section{B. Systematic Rank Structure of Electromechanical Equipment for Cleaning of Gas Emissions, Wastewater And Solid Waste}

The results of development of genetic systematic of electromechanical equipment designed to clean exhaust gases, wastewater and solid waste are presented in [3]. The object of the study, as mentioned above, is the functional class of magnetic separators [4-6]. The analysis of magnetic separators, depending on the environment where the purification is carried out. It is shown that there are three most commonly used structural classes of devices:

1. Devices with open magnetic systems, in which the working area with the magnetic field is external in relation to the poles of the system. These devices include suspended selfdischarging separators, electromagnetic pulleys, electromagnetic washers (purification of solid industrial waste); drum separators (purification of industrial solid waste and wastewater).

2. Filter separators (high gradient) belong to the class of combined technical systems and structurally unite the electromagnetic system (the source of the magnetic field) and the working body (filter matrix filled with ferromagnetic objects of a certain geometrical shape) are used for purification of wastewater, industrial fluids and process gases.

3. Magnetic devices for piping systems which have no source of magnetic field, and working elements (rods, bars) of which are made on the basis of magnetic solids and are used for the purification of technical fluids and process gases.

In a hierarchically organized structure of genetic systematics, the major taxonomic category is the species that is why it was determined the full species composition of the investigated class of devices for magnetic purification. We have considered the features of the electromechanical equipment for cleaning of gas emission, wastewater and solid waste systematics on the example of the magnetic separating devices with open magnetic systems [2, 3]. Availability of system information on the number of species and genetic structure of species allows to determine the ranked structure of the main taxonomic units of the class in which "Species" plays the function of the main systematic category for taxa of prior to species levels: "Species" $\rightarrow$ "Genus" $\rightarrow$ "Subfamily" $\rightarrow$ "Family".

Structural diversity of genus is determined by a combination of genetically related species, which are united by common spatial geometry of the primary field source $(\mathrm{CL}-$ cylindrical, CN - conical, FL - flat, TF - toroidal flat, TC toroidal cylinder, SP - spherical) [2]. Classes of magnetic purification electromechanical environment protecting equipment of rotational and translational motion have the status of subfamilies, as they unite the corresponding generic taxa by the nature of spatial movement. Structural class of electromechanical equipment for magnetic purification with the open magnetic system corresponds to the status of the family.

Analysis of the ranked structure of the systematics of electromechanical equipment for magnetic purification with open work area showed that the structural diversity of devices of rotary and translational motion is represented by 5 and 4 families respectively [3]. Subfamily of rotary motion devices is represented by 12 basic species with axially symmetric sources of magnetic field. Diversity of species of translational motion of electromechanical equipment subfamily for magnetic purification is sorted by 11 types with the travelling field sources. Given the identity of the genetic information in such structures as FL 2.2x = FL 2.2y and SP 2.2x = SP 2.2y (FL $2.2 \mathrm{x}, \ldots$, SP $2.2 \mathrm{y}$ - genetic codes) the total number of species of electromechanical objects of the investigated class was 21. The taxa were added to the ranked structure of the genetic taxonomy ("Species" $\rightarrow$ "Genus" $\rightarrow$ "Subfamily" $\rightarrow$ "Family") that take into account an artificial characteristic an environment where the magnetic purification (of gas emissions, wastewater, solid and industrial waste) is carried out. The ranked structure of the main taxonomic units of the functional class of electromechanical equipment for magnetic purification has the form shown in Fig. 1 [3].

Thus, the proposed systematics ranked structure consists of two blocks: block I contains taxa, which are determined by the periodic structure of the genetic classification of the primary sources of the field; block II - taxa, taking into account an artificial sign - a medium where the magnetic purification of gas emissions, waste water, solid and industrial waste takes place. 


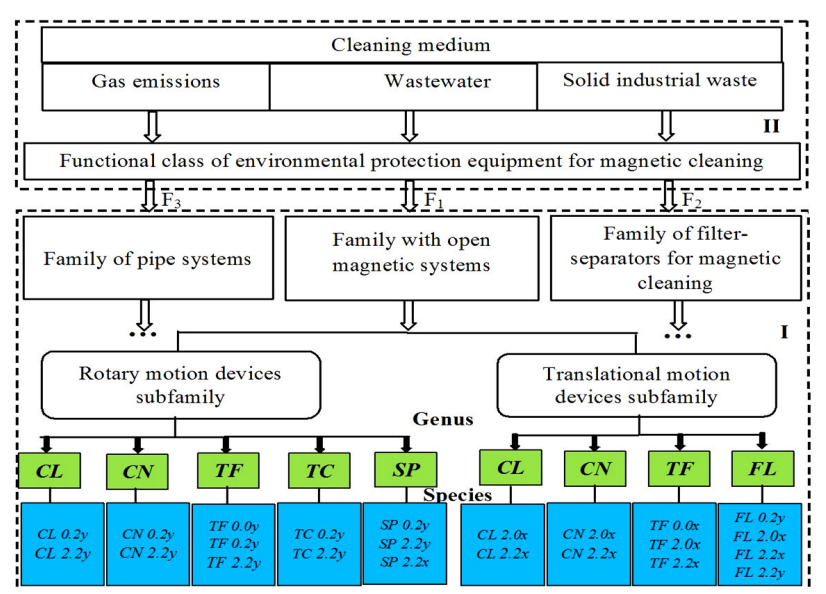

Fig. 1. Systematic rank structure of electromechanical equipment for magnetic cleaning.

\section{IV.INFORMATION RETRIEVAL SYSTEM STRUCTURE}

Ranked systematics structure underlies the design of information retrieval system structure for selection of technical solutions of electromechanical devices for purification of gas emission, wastewater and solid waste. The ability to determine the species composition of complete electromechanical equipment serving with the guarantee of the completeness of presentation.

Fig. 2 shows the minimum structure SQL - oriented database that satisfies the above requirements put forward and allows implementing the algorithm shown in Fig. 3.

The database (Fig. 2) consists of tables containing reference data, such as environments directory with types of contaminated environments; directory contaminants with pollutants; directory equipment genetic class with genetic codes (geometric forms) of equipment; directory motion type with types of motion of the working body.

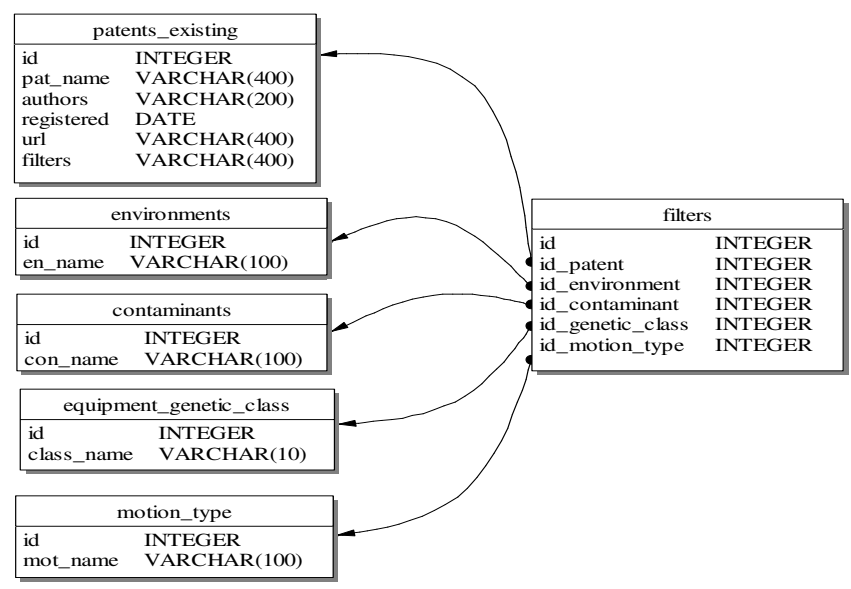

Fig. 2. Optional structure of SQL-oriented database.

Table patents existing contains information about patents registered in the database, patent name and information about its author, date of registration and placement of url- patent file. Patent file is saved in a Portable document format in any cloud storage, for example, Google drive or Dropbox, allowing retrieving data from any workstation with the Internet access. For rapid prototyping and its ease distribution, it was decided to implement the database in a way that would enable its access via the Internet.

Appearance version of the program is shown in Fig. 4. At the top of the information retrieval system screen controls shown parameters of patents selection. At the beginning, the selection elements are not involved. All registered in the system of patents are displayed at the bottom of the window. When the additional conditions of functioning equipment are selected, the list of patents that meet the required conditions is reduced. When opening a patent in a new browser window the uploaded to cloud storage file of a patent opens for its further viewing or printing.

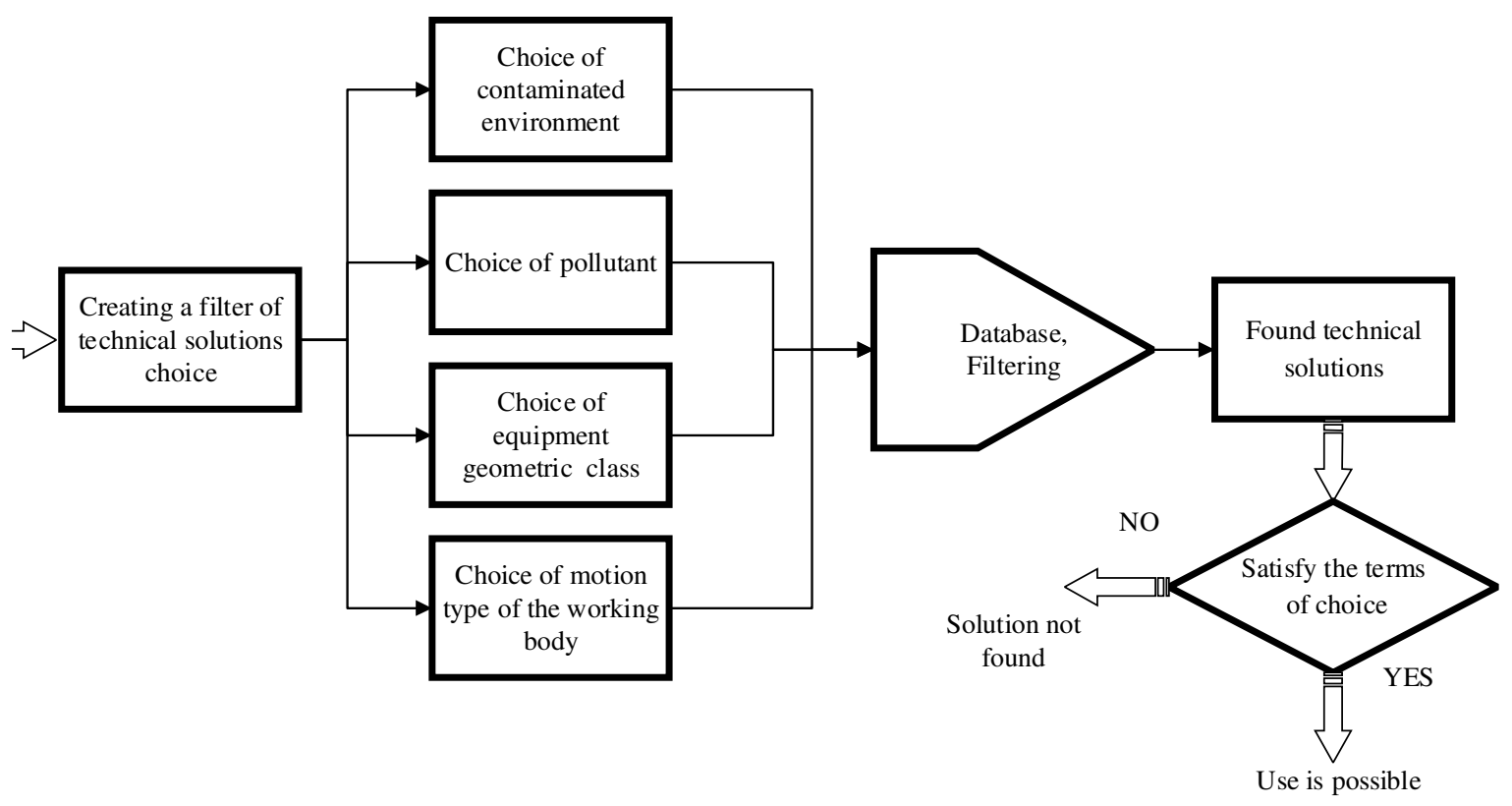

Fig. 3. Algorithm of the SQL-oriented database work. 


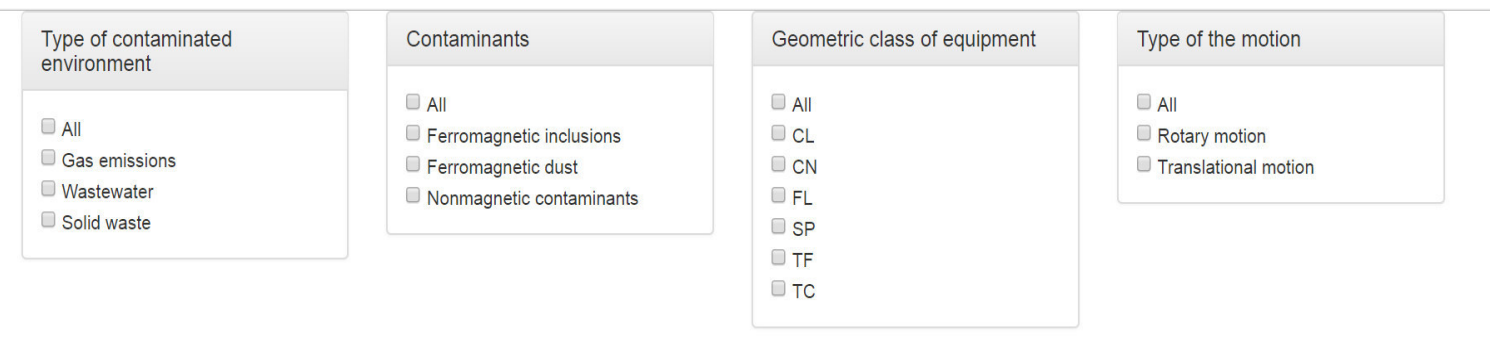

СПОСОБ МАГНИТНОЙ СЕПАРАЦИИ СЛАБОМАГНИТНЫХ ЖИДКОСТЕЙ ИЛИ ПЫЛЕГАЗОВЫХ ПРОДУКТОВ И МАГНИТНЫЙ СЕПАРАТОР ДЛЯ ЕГО ОСУЩЕСТВЛЕНИЯ

Лозин А.А., Арсенюк В.М.

МАГНИТНЫЙ СЕПАРАТОР

Сандуляк А.В., Сандуляк А.А., Ершова В.А., Лугинин Д.Б.

МАГНИТНЫЙ СЕПАРАТОР

Сандуляк А.В., Сандуляк А.А., Соколов В.К., Седнева Н.А.

Fig. 4. The main window with the filtered selection of the technical solutions.

Currently the program of selection of electromechanical devices is implemented as a single html-page. To store data and create user interaction technology JavaScript - Prototype oriented programming language screenwriting was used. JavaScript is an implementation of ECMAScript language (standard ECMA-262) and is the most widely used in browsers as a scripting language for adding interactivity to web pages [7].

Practical use of JavaScript in the developed software application framework is based on Vue. Unlike other monolithic frameworks, Vue is designed from the ground up to be incrementally adoptable. The core library is focused on the view layer only, and is very easy to pick up and integrate with other libraries or existing projects. On the other hand, Vue is also perfectly capable of powering sophisticated Single-Page Applications when used in combination with modern tooling and supporting libraries.

To increase the speed of prototyping software application database tables were designed as JSON-objects that are static in the body of html-pages. External data management of handbooks and patents has not yet been implemented.

\section{CONCLUSION}

The genetic methods of systematics were used to design information retrieval system for selecting electromechanical devices for purification of gas emission, wastewater and solid waste in order to ensure completeness and eliminate redundancy in data representation. Functional class of magnetic separators was chosen the research object. Ranked basic structure of regular class units underlies the design of the SQL - oriented database retrieval system structure.
Using information retrieval system to select electromechanical devices for purification of gas emission, wastewater and solid waste in the educational process allows future electrical engineers to get systematical information about the variety of electromechanical devices; to choose devices based on their operating conditions; to enter information into the electronic database and distribute it among users; to search prototypes when patenting new technical solutions; to avoid information overload, errors and unprofessional actions in the practice.

\section{REFERENCES}

[1] R. Bansal and S. Chawla, "Design and development of semantic webbased system for computer science domain-cpecific information retrieval," Perspectives in Science, vol.8, pp.330-333, 2016.

[2] V. F. Shinkarenko, M. V. Zagirnyak, and I. A. Shvedchikova, "Structural-Systematic Approach in Magnetic Separators Design," Studies in Computational Intelligence. Computational Methods for the Innovative Design of Electrical Devices, vol. 327, pp. 201-217, 2011.

[3] I. Soloshych and I. Shvedchykova, "Development of systematlics ranked structure of environmental protecting equipment for cleaning of gas emissions, wastewater and solid waste," Eastern-European Journal of Enterprise Technologies, no. 6/10 ( 84 ), pp. 17-23, 2016.

[4] I. A. Obertuffer, "Magnetic separation: a review of principles, devices and applications," IEEE Transactions On Magnetics, vol.mag-10, no. 2, pp. 223-238, 1974.

[5] J. Svoboda, Magnetic Methods for the Treatment of minerals. Amsterdam: Elsevier, 1987.

[6] K. H. Unkelbach, Magnetic separators mode of operation and applicability for the separation of materials. Köln: KHD Humboldt Wedag AG, 1990.

[7] A. Rauschmayer, Speaking JavaScript. O’Reilly Media, 2014. 